\title{
DNA methylation in development and human disease
}

\author{
Suhasni Gopalakrishnan, Beth O. Van Emburgh, and Keith D Robertson * \\ Department of Biochemistry \& Molecular Biology, UF-Shands Cancer Center Program in Cancer \\ Genetics, Epigenetics and Tumor Virology, University of Florida College of Medicine, Gainesville, \\ FL 32610
}

\section{Abstract}

DNA methylation is a heritable and stable epigenetic mark associated with transcriptional repression. Changes in the patterns and levels of global and regional DNA methylation regulate development and contribute directly to disease states such as cancer. Recent findings provide intriguing insights into the epigenetic crosstalk between DNA methylation, histone modifications, and small interfering RNAs in the control of cell development and carcinogenesis. In this review, we summarize the recent studies in DNA methylation primarily focusing on the interplay between different epigenetic modifications and their potential role in gene silencing in development and disease. Although the molecular mechanisms involved in the epigenetic crosstalk are not fully understood, unraveling their precise regulation is important not only for understanding the underpinnings of cellular development and cancer, but also for the design of clinically relevant and efficient therapeutics using stem cells and anticancer drugs that target tumor initiating cells.

\section{Keywords}

DNA methyltransferase; polycomb; cancer; ICF syndrome; histone modifications; gene regulation; chromatin

\section{Introduction}

DNA methylation is a covalent chemical modification of DNA occurring at cytosine residues in CpG dinucleotides. DNA methyltransferases (DNMTs) catalyze genome-wide DNA methylation and are associated with histone modifying enzymes (e.g. histone deacetylases (HDACs)), histone methyltransferases (SUV(39)H1/2 and EZH2), and ATP dependent chromatin remodeling enzymes (e.g. hSNF2H, LSH) (Fig. 1) [1,2]. DNA methylation is a stable epigenetic mark that regulates chromatin structure and gene expression involved in processes such as X chromosome inactivation, imprinting, embryogenesis, gametogenesis, and silencing of repetitive DNA elements [3]. In this review, we emphasize the dynamic nature of epigenetic gene regulation with a focus on the role of DNA methylation during mammalian development and human disease, and provide examples on how DNA methylation, together with other epigenetic silencing mechanisms such as histone methylation and chromatin remodeling factors, enables precise control over transcriptional gene silencing.

*Corresponding author: Department of Biochemistry \& Molecular Biology, University of Florida, College of Medicine, Box 100245, 1600 S.W. Archer Road, Gainesville, FL 32610. Phone: 352-392-1810; Fax: 352-392-2953; Email: keithr@ufl.edu.

Publisher's Disclaimer: This is a PDF file of an unedited manuscript that has been accepted for publication. As a service to our customers we are providing this early version of the manuscript. The manuscript will undergo copyediting, typesetting, and review of the resulting proof before it is published in its final citable form. Please note that during the production process errors may be discovered which could affect the content, and all legal disclaimers that apply to the journal pertain. 


\section{The mammalian DNA methylation machinery}

In mammals, DNMT3A and DNMT3B (Fig. 1) are responsible for establishing new DNA methylation patterns largely associated with retrotransposon sequences and satellite repeats in pericentromeric regions and differentially methylated regions (DMRs) of imprinted loci [1]. DNMT1, in contrast, copies existing methylation patterns following DNA replication and hence is predominantly considered the maintenance methyltransferase (Fig. 1) [1]. Mice lacking Dnmt3a developed to term, but died at about four weeks of age. In contrast, Dnmt3b null mice were not viable (embryonic lethality at E14.5-18.5) and showed multiple developmental defects, demonstrating that de novo methylation is an essential process for mammalian development [3]. DNMT3L is homologous to DNMT3A and DNMT3B within the N-terminal regulatory region and is highly expressed in germ cells. Although catalytically inactive, DNMT3L regulates DNMT3A and DNMT3B by stimulating their catalytic activity in vivo (Fig. 1) [4] and DNMT3L, like DNMT3A, is required for establishing genomic imprints. Mice deficient for Dnmt $3 L$ display genome-wide demethylation and developmental arrest at E8.5 and lack of Dnmt $3 L$ leads to a failure to establish maternal DNA methylation imprints in oocytes and male sterility due to defects in spermatogenesis [1].

\section{DNA methylation in pluripotency and differentiation}

Differentiation is an epigenetic process associated with the selective temporal activation of lineage specific genes and the regulated silencing of pluripotency genes. Dynamic regulation of de novo DNA methyltransferase expression occurs during development with higher levels in undifferentiated cells and reduced expression upon differentiation [5]. DNMTs are required for cellular differentiation during early embryonic development to regulate the systematic transcriptional inactivation of particular genes by promoter methylation. Key transcription factors, such as Oct4 and Nanog, form a transcriptional regulatory network that selectively activates genes essential for murine ES cell survival and proliferation while selectively repressing genes required for cell differentiation [6]. The Oct-4 enhancer/promoter region is hypomethylated in mouse ES cells while it is hypermethylated in trophoblast stem cells demonstrating epigenetic control of Oct 4 expression during early embryogenesis by DNA methylation and chromatin modification in a stage- and cell type-specific manner [7]. Subsequent studies showed that Oct4 and Nanog expression was progressively silenced by acquisition of histone $\mathrm{H} 3$ lysine 9 (H3K9) methylation, mediated by the SET domain histone methyltransferase protein G9a, leading to alterations in chromatin structure. Local heterochromatinization, due the recruitment of heterochromatin protein 1 (HP1) at H3K9 methylated chromatin, is required for subsequent de novo methylation at the Oct4 and Nanog promoters. Moreover, in vitro differentiation of pluripotent cells lacking G9a or the orphan nuclear receptor family member GCNF (also a transcriptional repressor of Oct4 [8]) leads to activation of Oct4 expression due to promoter hypomethylation $[9,10]$. Interestingly, both Dnmt3a and Dnmt3b function synergistically within a protein complex and stimulate each other's activity to methylate the Oct4 and Nanog promoters in differentiating mouse embryonic carcinoma (EC) and ES cells [11]. A study of Oct4 transcription by injecting mammalian somatic cell nuclei into Xenopus oocytes demonstrated that DNA demethylation is necessary for Oct4 transcription and subsequent epigenetic reprogramming, suggesting selective promoter demethylation precedes gene reprogramming [12,13]. This finding, in turn, suggests that reprogramming deficiencies in cloned embryos arise from abnormal removal of repressive marks and impaired DNA methylation patterns [14]. Therefore, DNA methylation may augment or lock in stable repression of pluripotency-associated genes $[15,16]$.

A comprehensive DNA methylation analysis of 16,000 human gene promoters using methylated DNA immunoprecipitation (MeDIP) combined with high-density DNA microarrays revealed large numbers of $\mathrm{CpG}$ island promoters to be hypomethylated even when 
transcriptionally inactive in somatic cells. These regions also contained elevated levels of H3K4 dimethylation that may serve as a defensive marker against DNA methylation in high CpG-density promoters [17]. The recent finding that Dnmt3L recognizes unmethylated lysine 4 on histone $\mathrm{H} 3$ and induces de novo DNA methylation by recruitment or activation of Dnmt3a2 $[18,19]$, provides a novel mechanistic link between these two epigenetic pathways and provides insights into how DNA methylation may complement other epigenetic regulatory mechanisms. Dnmt3L may help interpret preexisting histone marks established at different genomic regions thus enabling acquisition of DNA methylation for long-term silencing. Therefore, DNA methylation represents a unique transcription program that forms the basis of cell differentiation.

More insights into the regulation of pluripotency by DNA methylation come from recent studies involving the mammalian RNase III family nuclease Dicer. Dicer initiates RNA interference (RNAi) by processing the small RNAs that determine the specificity of gene silencing pathways. Loss of Dicer compromises maturation of microRNAs (miRNAs) and leads to defects in gene silencing and differentiation [20]. Dicer-deficient mice display decreased expression of Dnmts and global DNA methylation defects leading to telomere recombination and aberrant telomere elongation in a miR-290 cluster-dependent manner [21]. Transcriptome analysis of Dicer-null ES cells revealed downregulation of the miR-290 cluster and repression of de novo DNA methyltransferases [22]. The mammalian miR-290 cluster specifically silences expression of the transcription factor retinoblastoma-like 2 (Rbl2) and other transcriptional repressors. MiR-290 cluster downregulation, in turn, leads to posttranscriptional upregulation of Rbl2 and consequent transcriptional repression of Dnmt3a and Dnmt3b along with DNA methylation defects. Proper initiation of Oct4 silencing through the accumulation of repressive histone marks occurs normally in Dicer-null ES cells, but subsequent $O c t 4$ promoter de novo methylation is abolished, preventing establishment of stable Oct4 repression. Interestingly, the defective DNA methylation is rescued by ectopic expression of Dnmts or by transfection of the miR-290 cluster miRNAs, indicating that miRNAs control de novo DNA methylation in ES cells [22]. Taken together, these studies suggest that DNA methylation is an essential regulatory mechanism ensuring proper establishment of gene expression patterns for target genes that are crucial during epigenetic reprogramming in normal development.

\section{Links between DNA methylation and other epigenetic regulators}

An important link between histone $\mathrm{H} 3 \mathrm{~K} 9$ methylation and DNA methylation in mammals was identified when Suv39h1 HMTase directed H3K9 trimethylation was shown to be required for recruiting Dnmt3b-dependent DNA methylation to pericentromeric repeats (Fig. 1). Murine ES cells lacking Suv39h1/2 display an altered DNA methylation profile at pericentromeric satellite repeats, but not at other repeat sequences [23]. Recent genetic and biochemical results indicate that the mammalian ubiquitin-like protein, containing PHD and RING finger domains 1(Uhrf1 or NP95 (nuclear protein 95) in mouse and ICBP90 (inverted CCAAT box binding protein 90) in human), binds to methylated DNA. Np95 null ES cells display demethylated interspersed repeats and altered methylation at imprinted loci and tandem repeats. Np95 preferentially binds to hemimethylated DNA via its SET and RING finger associated (SRA) domain. Np95 binding to hemimethylated DNA is similar to Dnmt1's preference for hemimethylated substrates and Np95 directly interacts with Dnmt1 (Fig. 1) [24,25]. DNA methylation-associated factors like SUV39H1 and Np95 may be important for reinforcing the stability of heterochromatin regions and thereby protecting genome integrity.

Studies also show that Lsh (lymphoid specific helicase), a member of the SNF2-helicase family of chromatin remodeling proteins, is involved in regulating DNA methylation patterns during embryonic development. Lsh is required for methylation of select imprinted loci and silencing 
of IAP retrotransposons [26]. Deletion of $L s h$ perturbs DNA methylation patterns in mice causing reduced de novo methylation without affecting maintenance methylation [27]. In vivo and in vitro pull down assays demonstrated that Lsh recruits Dnmt1, Dnmt3b, and HDACs to establish a transcriptionally repressive chromatin structure independent of the enzymatic activities of Dnmts (Fig. 1) [28]. Recent studies indicate that Lsh associates with Hox genes and regulates Dnmt3b binding, DNA methylation, and silencing of Hox genes during development. Lsh inactivation resulted in decreased DNMT3B and polycomb group (PcG) protein complex binding. There are two main polycomb complexes in mammals, PRC1 (composed of HPH, RING1, BMI1, HPC (1-4)) and PRC2 (composed of EED, EZH2, YY1, SU(Z)12) (Fig.2). Inactivation of Lsh also leads to loss of PRC1 and PRC2-associated chromatin marks, suggesting that Lsh and DNA methylation are important for complete assembly and activity of the polycomb complexes [29]. This study demonstrates that the activities of PRC1 and PRC2 are tightly connected to DNA methylation and that establishment of the complex network of physiological feedback loops by epigenetic factors reinforces DNA methylation and silencing of PRC targets with implications for development and disease states. Additional evidence for polycomb-DNMT interactions will be presented in the sections on cancer and ICF syndrome.

\section{DNA methylation and cancer}

Epigenetic defects that are hallmarks of cancer include global genomic hypomethylation and locus-specific hypermethylation of $\mathrm{CpG}$ islands. Hypomethylation is foremost associated with repetitive regions of DNA and transposable elements, although hypomethylation also occurs within promoters of normally silenced genes. These alterations, in turn, lead to genomic instability. Gene-specific hypermethylation frequently occurs in the promoter regions of tumor suppressor genes and acts as one or both "hits" in Knudson's two-hit hypothesis. Mechanisms underlying these defects are poorly understood, but much research has focused on the DNA methyltransferases. It has become increasingly clear, however, that the DNMTs do not work alone in regulating cellular DNA methylation patterns, but rather they are dictated by a complex interaction between DNMTs and chromatin-associated factors such as polycomb proteins. Aberrant methylation typically found in cancer may be related to alterations in these interactions disrupting the precise regulation of the epigenome of normal cells. The discussion of the origin of cancer has recently shifted to the possibility that cancer is initiated by defects in tissue-specific stem cells. This places the DNMTs and methylation firmly into the spotlight, as they are an intricate part of stem cell regulation and development.

\subsection{DNA hypomethylation}

Genomic hypomethylation has multiple potential consequences, including chromosomal instability, aberrant activation of endogenous retroviral elements and oncogenes, and loss of imprinting [30]. A decrease in global levels of methylation is largely attributed to loss of methylation at normally heavily methylated repeat elements including satellite repeats (e.g. Sat2) and retrotransposons (e.g. LINEs). What events take place to lead to such large-scale changes in methylation? Knockout of Dnmt $3 b$ in ES cells resulted in loss of methylation at minor satellite repeats, which was not observed in Dnmt3a knockouts [31]. Individuals with immunodeficiency, centromeric instability, and facial anomalies (ICF) syndrome, which is associated with germ-line DNMT3B mutations, also exhibit decreased Sat2 methylation making aberrant DNMT3B function an attractive target for causing hypomethylation. A mouse model of intestinal cancer, the $\mathrm{Apc}^{\mathrm{Min} /+}$ or $\mathrm{Min}$ (multiple intestinal neoplasia) mouse combined with global genomic hypomethylation, due to a Dnmt1 hypomorph, revealed that even though there was loss of heterozygosity at the Apc locus and an increase in colonic microadenomas, these lesions did not progress to macroscopic tumors [32]. However, tumors of the liver developed, in the Dnmtl hypomorphic Min mice demonstrating that effects of hypomethylation 
are tissue specific. In the absence of the Min background, hypomethylation resulting from a hypomorphic Dnmtl allele resulted in T-cell lymphomas associated with chromosomal instability [33]. Effects on chromosomal stability were also noted in a mouse sarcoma model combining the Dnmtl hypomorphic allele with Neurofibromatosis 1 (NfI) and $p 53$ mutations [34]. As with Dnmt1 deficient Min mice [32], Min mice with a conditional intestinal Dnmt3b knockout resulted in reduced frequency of macroscopic tumors but did not affect microadenoma frequency [35]. The differences between these models may be attributed to the global hypomethylation resulting from the Dnmt1 hypomorph and therefore loss of heterozygosity of $A p c$, which would not be expected in the absence of Dnmt3b due to more limited genomic hypomethylation [35]. Based on these results [32,35], it appears that hypomethylation resulting from a loss of Dnmt1 promotes the early stages of colon cancer, but both Dnmt 1 and Dnmt $3 \mathrm{~b}$ are required for progression of intestinal adenomas.

Consequences of hypomethylation are not limited to chromosomal stability, but also result in aberrant expression of oncogenes and loss of imprinting. For example, the synuclein- $\gamma$ gene $(S N C G)$, whose expression is usually restricted to neurons, becomes demethylated in both breast and ovarian cancer [36]. Overexpression of SNCG results in a more aggressive breast cancer phenotype [37]. Interestingly, a gene involved in epigenetic regulation, the zinc finger protein and paralog of CTCF, Brother of the Regulator of Imprinted Sites (BORIS/CTCFL) is demethylated in epithelial ovarian cancers resulting in increased expression compared to normal ovarian tissue [38]. This aberrant expression may lead to further alteration of the epigenome in cancer cells. Since expression of BORIS/CTCFL is typically limited to testicular germ cells it is therefore classified as a cancer-testes antigen/gene. Hypomethylation also contributes to loss of imprinting of $I G F 2$ in colon cancer [39]. A serious consequence predicted to result from DNA hypomethylation is transcriptional activation of silenced retrotransposons. At this time there is limited evidence for this type of activity initiating cancer. Early studies revealed that endogenous retroviral-like IAP transcripts are increased in embryos of Dnmt $1^{-/-}$mice [40]. Insertion of LINE1 elements into genes have in rare cases been observed in colon cancer [41]. A recent study by Howard et al. showed for the first time that a new IAP element became inserted at the Notchl locus in lymphomas of Dnmtl deficient mice [42]. This mouse model demonstrates that hypomethylation causes not only generalized chromosomal instability, but also locus-specific instability.

\subsection{DNA hypermethylation}

Hypermethylation of promoter $\mathrm{CpG}$ islands is frequent in tumors and is associated with aberrant tumor suppressor gene silencing. In certain tissues such as the pancreas and kidney, hypermethylation is an early event and the number of aberrant hypermethylation events increases progressively from a precancerous to a cancerous state $[43,44]$. The importance of hypermethylation of genes in cancer has become so well recognized that databases such as PubMeth (www.pubmeth.org) are now available allowing one to search for evidence of methylation of a gene of interest in different cancer types.

An important issue in understanding cancer development is why and how only certain genes become hypermethylated. A great deal of emphasis is rightfully placed on the DNA methyltransferases. Our knowledge of how these enzymes are regulated and targeted to their respective sequences, though, is still very limited. The HCT116 colorectal carcinoma cell line is one of the most frequently studied cancer cell lines due to the availability of isogenic DNMT knockout lines. DNMT1 knockout resulted in loss of only 20\% of DNA methylation while DNMT3B knockout resulted in loss of <3\% [45,46]. DNMT1 plus DNMT3B knockout (double knockout or DKO) cells displayed a much greater decrease in DNA methylation $(>95 \%)$ demonstrating the overlapping and synergistic roles of DNMT1 and DNMT3B in maintaining cellular DNA methylation [45]. Results obtained with the HCT116 knockout 
model differ from a conditional mouse embryonic fibroblast (MEF) Dnmtl knockout model and an HCT116 DNMT1 conditional catalytic domain knockout [47,48]. Dnmt1 -/- MEFs underwent apoptosis while HCT116 cells lacking catalytically active DNMT1 underwent mitotic catastrophe. It was later determined that the original HCT116 DNMT1 knockout cells expressed a hypomorphic form of DNMT1 (lacking the PCNA binding domain) due to alternative splicing [49]. Taken together, these findings underscore the importance of DNMT1 for cell survival [50]. Depletion of DNMT3B, but not DNMT3A, using antisense knockdown methods in cancer cells resulted in decreased cell growth or apoptosis. Ectopic expression of the catalytically active DNMT3B2 splice variant or the inactive DNMT3B3 splice variant overcame the antiproliferative effect [51] suggesting that DNMT3B is also essential to cancer cell survival. Conditionally overexpressing Dnmt3b in the Min mouse resulted in enhanced adenoma formation, loss of imprinting at the Igf2 locus, and silencing of the Sfrp tumor suppressor genes by promoter hypermethylation. This outcome was dependent on Dnmt3b's enzymatic activity since expression of inactive Dnmt3b splice variants (Dnmt3b3 and Dnmt3b6) and Dnmt3a showed little increase in adenoma formation [52]. Overexpression of Dnmt1 in ES cells also resulted in loss of imprinting at the Igf2 locus (not other imprinted genes), but when these modified ES cells were injected into blastocysts embryonic lethality resulted [53]. Collectively, these models emphasize that DNMTs influence tumor formation by targeting specific genes for methylation.

\section{DNA methylation and polycomb (PcG) complexes: Linking development to cancer}

Interesting new studies suggest that DNA methylation and PcG-mediated repression may coordinate to stabilize silencing at polycomb target genes. For example, DNMTs physically interact with components of both PcG protein complexes PRC1 and PRC2 (Fig. 1, Fig. 3) [2, 54,55]. The interaction of EZH2 and EED with DNMT1, DNMT3A, and DNMT3B by coimmunoprecipitation assays and loss of silencing at EZH2 target genes after RNAi-mediated knockdown of DNMTs, demonstrate that repression of EZH2 target genes requires both EZH2 and DNMTs. This study also suggested that EZH2 mediates recruitment of DNMTs to regulatory regions of EZH2 target genes. Although the mechanism of DNMT recruitment by EZH2 is not fully elucidated, EZH2-mediated H3K27 methylation may be a requirement [2]. This is mechanistically similar to the recruitment of DNMTs to regions containing SUV39H1\&2-mediated H3K9 trimethylation marks, suggesting a link between polycombmediated histone methylation and DNA methylation and their coordinated role in transcriptional repression $[23,56]$. As is often the case, the link between DNA methylation and polycomb may be more complicated than suggested by Vire et al. because an additional report showed that once promoters acquire dense DNA hypermethylation, EZH2 is no longer required to maintain DNA methylation [57]. In this state, the maintenance function of DNMT1 may suffice or DNA methylation may help to maintain PRC1 at these promoters (Fig. 3).

While DNA methylation at EZH2 target genes adds another layer of repression to lock in the silent state, it might also help recruit the PRC1 complex. Following initiation of silencing by PRC2, PRC1 recruitment leads to maintenance of a silent chromatin state [58]. DNMT1 collaborates with EZH2 to facilitate proper localization of PRC1 components, such as BMI1, to polycomb complexes organized into discrete nuclear structures called PcG bodies [54]. DNMT1 also interacts with BMI1 via the DMAP1 protein as a bridge [59]. Interestingly, Cbx4 (hPC2), a PRC1 complex component, was identified as a SUMO E3 ligase and interaction partner of Dnmt3a (Fig. 1,3) [55]. Moreover, another recent study showed that Cbx4 also interacts with DNMT3B and that DNMT3B functions as a corepressor of Cbx4-mediated transcriptional repression independent of its DNA methyltransferase activity [60]. Cbx4 may function as a linker between PRC1-mediated histone methylation and DNA methylation. Given that $\mathrm{xDnmt} 1$ was recently shown to act as a transcriptional repressor independent of its catalytic 
activity at unmethylated promoters [61], it is conceivable that mammalian Dnmts also possess such properties and are inactive with respect to DNA methylation when initially recruited by EZH2 and become activated later by an unknown regulatory signal [56] (Fig. 3). Since Cbx4 also recognizes trimethylated $\mathrm{H} 3 \mathrm{~K} 9$ through its $\mathrm{N}$-terminal chromodomain [62], it may subsequently recruit Dnmt3a to these regions [55]. Alternatively, Dnmts already bound at target genes may recruit $\mathrm{Cbx} 4$ and other PRC1 components and $\mathrm{Cbx} 4$ may modify the regulation of DNA methyltransferases by promoting their SUMO modification (Fig. 3). Sumoylation might promote or inhibit protein-protein interactions and therefore have an effect on transcription indirectly, perhaps by preventing ubiquitin-mediated degradation or by altering the subcellular localization of interacting protein partners, leading to differential recruitment of activities that activate or repress gene transcription [63].

Additional studies have revealed connections between DNMTs and polycomb components in ES cells that further underscore the important link between pluripotency and tumorigenesis $[15,16,64]$. During development, the chromatin of many pluripotency-associated genes such as the Sox, Hox, Pou and Pax families, contain a bivalent pattern of epigenetic marks that includes both repressive (H3K27 trimethylation) and active (H3K4 trimethylation) histone marks (Fig. 2). Lineage control genes positioned within these poised chromatin states also showed the presence of $\mathrm{H} 3 \mathrm{~K} 4$ methylation at $\mathrm{CpG}$ islands. A recent genome-wide study of promoter epigenetic modifications in ES cells has further clarified the relationships between DNA methylation and histone marks [65]. Four main patterns were identified, (1) highly active genes enriched for H3K4 trimethylation (including pluripotency genes), (2) bivalently marked repressed genes (some with and some without polycomb) largely involved in developmental processes, (3) a small group of repressed genes marked only by H3K27 trimethylation, and (4) repressed genes marked only by DNA methylation that were enriched for late lineage specification genes (Fig. 2). Approximately 50\% and 70\% of the genes in classes two and three, however, were also enriched for DNA methylation further emphasizing the DNA methylationH3K27 methylation link. Surprisingly, some actively transcribed genes and genes enriched for H3K4 trimethylation also contained DNA methylation, suggesting that this mark can be overridden in certain situations.

An important unanswered question in the DNA methylation field is why only certain gene promoters become hypermethylated in cancer while others do not. This may be further influenced by tissue of origin of the particular cancer. An exciting but still controversial hypothesis for how aberrant DNA hypermethylation may be 'targeted' to select genes in cancer cells is related to idea that cancers arise from a transformed stem cell-like cell, or tumor stem cell. The tumor stem cell hypothesis (Fig. 4) states that tissue-specific stem or progenitor cells undergo oncogenic transformation, perhaps due to environmental insults or endogenous processes like inflammation or wound healing. These tumor stem cells (or tumor initiating cells, TICs) retain the capacity for unlimited self-renewal as well as the ability to differentiate. They generally represent a very minor fraction of the tumor volume. In contrast, the aberrantly differentiated progeny of TICs comprise the bulk of the tumor that is commonly treated by surgery and radiation/chemotherapy and these cells have limited growth capacity. Polycomb proteins and the gene targets of polycomb-mediated repression appear important for both cell types. One of the first reports linking polycomb targets and genes hypermethylated in cancer showed that genes commonly targeted for promoter hypermethylation were enriched for the H3K27 trimethylation mark mediated by PRC2 [15]. A subsequent study by Ohm et al. compared the DNA methylation and chromatin marks at genes subject to tumor-specific DNA hypermethylation in ES, embryonic carcinoma (EC), and tumor cells [66]. Interestingly, genes bound by polycomb in ES cells were generally unmethylated in EC cells but were densely hypermethylated in tumor cells. The bivalent status of the histone marks at these genes in ES cells was largely maintained in EC cells with the addition of $\mathrm{H} 3 \mathrm{~K} 9 \mathrm{di}-$ and trimethylation. This result suggests that EC cells are in an intermediate state between stem cells and tumor cells 
and that acquisition of aberrant histone marks, like H3K9 methylation, may be one of the early steps in transitioning polycomb target genes to a repressed but developmentally responsive chromatin state in ES cells to one permanently locked in the "off" position by DNA hypermethylation in TICs (Fig. 3). This, in turn, would render the gene unresponsive to normal developmental cues and likely provide the cell with a growth advantage. Two additional papers have also noted a highly non-random association between genes subject to aberrant cancerspecific DNA hypermethylation and genes bound by polycomb in normal cells [16,67]. Taken together, these results suggest a potential 'targeting' mechanism for aberrant DNA methylation of select genes in cancer, namely that genes normally repressed by polycomb proteins are preferentially susceptible to acquiring aberrant DNA methylation in cancer (Fig. 3). This model could also account for differences in DNA methylation targets between different cancers if polycomb targets genes are also regulated in a tissue-specific manner. An additional important question to be resolved is whether DNMTs are always complexed with polycomb proteins but are inactive in normal cells or they are recruited later. Are there differences in DNMTpolycomb associations after differentiation of ES cells? The signal or modification that activates the DNMT to methylate polycomb target genes also needs to be resolved. Given the enzymatic activities present in polycomb complexes, including histone methylation,

ubiquitination, and sumoylation, post-translational modifications directly or indirectly altering DNMT activity and/or recruitment is an attractive mechanism (Fig. 3). Future experiments will no doubt test these and other possible mechanisms.

\section{Immunodeficiency, centromeric instability and facial anomalies (ICF) as a developmental disease}

ICF syndrome is a rare autosomal recessive disorder caused by mutations in DNMT3B. Patients with ICF syndrome display variable combined immunodeficiency, facial anomalies, developmental delay, and mental retardation [68]. Centromeric instability, another hallmark of ICF B cells, is caused by loss of methylation within classical satellites (sat 2 and 3) at the pericentromeric regions of chromosomes 1, 9, and 16 [68]. In addition, genes on the inactive $\mathrm{X}$ chromosome, the highly restricted tissue specific/immunogenic cancer-testes genes, and non-satellite repeats D4Z4 and NBL2, are demethylated [69-71].

Mouse models of ICF syndrome mirror many of the characteristics of ICF patients, including hypomethylation of repetitive sequences, distinct craniofacial anomalies, and defects in the immune system, indicating that Dnmt3b plays an essential role at different stages of mouse development [72]. Most of the mutant forms of DNMT3B in ICF cells showed decreased activity compared to the wild-type enzyme [73]. Some mutants that did not show reduced enzyme activity rather resulted in disruption of the interaction between Dnmt3b and Dnmt3L [74].

Our group recently reported the use of expression microarray profiling to identify genes under the control of DNMT3B's DNA methylation and repression functions [75]. Nearly 800 genes displayed an altered pattern of expression and a significant fraction of these were involved in developmental processes. DNA methylation analysis of upregulated genes in ICF cells revealed that some genes do indeed have DNA methylation defects, although many of them are subtle. For example, the $L H X 2$ homeobox gene, a polycomb target [76], was approximately 10-20\% methylated in normal lymphoblastoid cell lines (LCLs) and this level was reduced to less than $3 \%$ in ICF LCLs. Other genes displayed no change in DNA methylation despite the expression change. Interestingly, while DNA methylation changes were often modest, large changes in the histone code were observed at affected genes. Loss of H3K27 and H3K9 trimethylation at upregulated genes was a consistent finding, regardless of DNA hypomethylation. Furthermore, both DNMT3B and SUZ12 bound most of the examined genes in normal LCLs and this binding was reduced or lost in ICF cells. Global levels of H3K4 and H3K27 methylation, and H2AK119 
monoubiquitination were globally disrupted in ICF cells. This data therefore further strengthens the links between DNMT3B and polycomb complexes that we have discussed previously since the most consistently altered modifications at a gene-specific and whole genome level in ICF cells were those mediated by PRC1 and PRC2. Expression of a number of developmental genes, including homeobox genes and sonic hedgehog, were also altered in ICF cells. In addition to our recent work, an analysis of the location of genes on the $\mathrm{X}$ and $\mathrm{Y}$ chromosomes within their specific chromosome territories in ICF cells, which are known to have defects in $X$ inactivation [69], was recently reported [77]. Genes that underwent hypomethylation on the inactive $\mathrm{X}$ of female ICF cells became relocalized toward the outside of the chromosome territory, consistent with their increased expression. Large adjacent regions were also relocalized regardless of whether a change in transcription occurred, indicating that loss of DNMT3B function results in alterations to genome structure that extend significantly beyond hypomethylated regions. Such changes may also account for some of the alterations in the expression of genes lacking defects in DNA methylation.

\section{Conclusions}

Throughout the course of this review, we have discussed the role of DNA methylation in development and disease and its connections with other epigenetic modifications. It is becoming clear that multiple epigenetic pathways control cell fate and disease states and the outcome of cellular events is determined by the balance and timing of epigenetic regulators. Moreover, the last ten years has seen a large increase in number of enzymes capable of modifying the chromatin and thus introducing a complex network of physiological feedback loops in epigenetic regulation in various cellular processes. An understanding of the role of DNA methylation and the interplay between other epigenetic regulatory pathways, particularly the relationship between DNA methylation and polycomb proteins, will not only provide insights into the regulation of cell differentiation, development, and disease, but should also help to develop efficient stem cell-related therapeutics and clinically useful chemical inhibitors.

\section{Acknowledgments}

We apologize to colleagues whose work was not cited due to space constraints.

\section{References}

1. Goll MG, Bestor TH. Eukaryotic cytosine methyltransferases. Annu Rev Biochem 2005;74:481-514. [PubMed: 15952895]

2. Vire E, Brenner C, Deplus R, Blanchon L, Fraga M, Didelot C, Morey L, Van Eynde A, Bernard D, Vanderwinden JM, Bollen M, Esteller M, Di Croce L, de Launoit Y, Fuks F. The Polycomb group protein EZH2 directly controls DNA methylation. Nature 2006;439:871-874. [PubMed: 16357870]

3. Li E. Chromatin modification and epigenetic reprogramming in mammalian development. Nat Rev Genet 2002;3:662-673. [PubMed: 12209141]

4. Suetake I, Shinozaki F, Miyagawa J, Takeshima H, Tajima S. DNMT3L stimulates the DNA methylation activity of Dnmt3a and Dnmt3b through a direct interaction. J Biol Chem 2004;279:27816-27823. [PubMed: 15105426]

5. Watanabe D, Suetake I, Tada T, Tajima S. Stage- and cell-specific expression of Dnmt3a and Dnmt3b during embryogenesis. Mech Dev 2002;118:187-190. [PubMed: 12351185]

6. Loh YH, Wu Q, Chew JL, Vega VB, Zhang W, Chen X, Bourque G, George J, Leong B, Liu J, Wong KY, Sung KW, Lee CW, Zhao XD, Chiu KP, Lipovich L, Kuznetsov VA, Robson P, Stanton LW, Wei CL, Ruan Y, Lim B, Ng HH. The Oct4 and Nanog transcription network regulates pluripotency in mouse embryonic stem cells. Nat Genet 2006;38:431-440. [PubMed: 16518401]

7. Hattori N, Nishino K, Ko YG, Hattori N, Ohgane J, Tanaka S, Shiota K. Epigenetic control of mouse Oct-4 gene expression in embryonic stem cells and trophoblast stem cells. J Biol Chem 2004;279:17063-17069. [PubMed: 14761969] 
8. Fuhrmann G, Chung AC, Jackson KJ, Hummelke G, Baniahmad A, Sutter J, Sylvester I, Scholer HR, Cooney AJ. Mouse germline restriction of Oct4 expression by germ cell nuclear factor. Dev Cell 2001;1:377-387. [PubMed: 11702949]

9. Feldman N, Gerson A, Fang J, Li E, Zhang Y, Shinkai Y, Cedar H, Bergman Y. G9a-mediated irreversible epigenetic inactivation of Oct-3/4 during early embryogenesis. Nat Cell Biol 2006;8:188194. [PubMed: 16415856]

10. Gu P, Le Menuet D, Chung AC, Cooney AJ. Differential recruitment of methylated CpG binding domains by the orphan receptor GCNF initiates the repression and silencing of Oct 4 expression. Mol Cell Biol 2006;26:9471-9483. [PubMed: 17030610]

11. Li JY, Pu MT, Hirasawa R, Li BZ, Huang YN, Zeng R, Jing NH, Chen T, Li E, Sasaki H, Xu GL. Synergistic function of DNA methyltransferases Dnmt3a and Dnmt3b in the methylation of Oct4 and Nanog. Mol Cell Biol 2007;27:8748-8759. [PubMed: 17938196]

12. Simonsson S, Gurdon J. DNA demethylation is necessary for the epigenetic reprogramming of somatic cell nuclei. Nat Cell Biol 2004;6:984-990. [PubMed: 15448701]

13. Wernig M, Meissner A, Foreman R, Brambrink T, Ku M, Hochedlinger K, Bernstein BE, Jaenisch R. In vitro reprogramming of fibroblasts into a pluripotent ES-cell-like state. Nature 2007;448:318324. [PubMed: 17554336]

14. Boiani M, Eckardt S, Scholer HR, McLaughlin KJ. Oct4 distribution and level in mouse clones: consequences for pluripotency. Genes Dev 2002;16:1209-1219. [PubMed: 12023300]

15. Schlesinger Y, Straussman R, Keshet I, Farkash S, Hecht M, Zimmerman J, Eden E, Yakhini Z, BenShushan E, Reubinoff BE, Bergman Y, Simon I, Cedar H. Polycomb-mediated methylation on Lys27 of histone H3 pre-marks genes for de novo methylation in cancer. Nat Genet 2007;39:232-236. [PubMed: 17200670]

16. Widschwendter M, Fiegl H, Egle D, Mueller-Holzner E, Spizzo G, Marth C, Weisenberger DJ, Campan M, Young J, Jacobs I, Laird PW. Epigenetic stem cell signature in cancer. Nat Genet 2007;39:157-158. [PubMed: 17200673]

17. Weber M, Hellmann I, Stadler MB, Ramos L, Paabo S, Rebhan M, Schubeler D. Distribution, silencing potential and evolutionary impact of promoter DNA methylation in the human genome. Nat Genet 2007;39:457-466. [PubMed: 17334365]

18. Jia D, Jurkowska RZ, Zhang X, Jeltsch A, Cheng X. Structure of Dnmt3a bound to Dnmt3L suggests a model for de novo DNA methylation. Nature 2007;449:248-251. [PubMed: 17713477]

19. Ooi SK, Qiu C, Bernstein E, Li K, Jia D, Yang Z, Erdjument-Bromage H, Tempst P, Lin SP, Allis $\mathrm{CD}$, Cheng X, Bestor TH. DNMT3L connects unmethylated lysine 4 of histone $\mathrm{H} 3$ to de novo methylation of DNA. Nature 2007;448:714-717. [PubMed: 17687327]

20. Bushati N, Cohen SM. microRNA functions. Annu Rev Cell Dev Biol 2007;23:175-205. [PubMed: 17506695]

21. Benetti R, Gonzalo S, Jaco I, Munoz P, Gonzalez S, Schoeftner S, Murchison E, Andl T, Chen T, Klatt P, Li E, Serrano M, Millar S, Hannon G, Blasco MA. A mammalian microRNA cluster controls DNA methylation and telomere recombination via Rbl2-dependent regulation of DNA methyltransferases. Nat Struct Mol Biol 2008;15:268-279. [PubMed: 18311151]

22. Sinkkonen L, Hugenschmidt T, Berninger P, Gaidatzis D, Mohn F, Artus-Revel CG, Zavolan M, Svoboda P, Filipowicz W. MicroRNAs control de novo DNA methylation through regulation of transcriptional repressors in mouse embryonic stem cells. Nat Struct Mol Biol 2008;15:259-267. [PubMed: 18311153]

23. Lehnertz B, Ueda Y, Derijck AA, Braunschweig U, Perez-Burgos L, Kubicek S, Chen T, Li E, Jenuwein T, Peters AH. Suv39h-mediated histone H3 lysine 9 methylation directs DNA methylation to major satellite repeats at pericentric heterochromatin. Curr Biol 2003;13:1192-1200. [PubMed: 12867029]

24. Bostick M, Kim JK, Esteve PO, Clark A, Pradhan S, Jacobsen SE. UHRF1 plays a role in maintaining DNA methylation in mammalian cells. Science 2007;317:1760-1764. [PubMed: 17673620]

25. Sharif J, Muto M, Takebayashi S, Suetake I, Iwamatsu A, Endo TA, Shinga J, Mizutani-Koseki Y, Toyoda T, Okamura K, Tajima S, Mitsuya K, Okano M, Koseki H. The SRA protein Np95 mediates epigenetic inheritance by recruiting Dnmt1 to methylated DNA. Nature 2007;450:908-912.

[PubMed: 17994007] 
26. De La Fuente R, Baumann C, Fan T, Schmidtmann A, Dobrinski I, Muegge K. Lsh is required for meiotic chromosome synapsis and retrotransposon silencing in female germ cells. Nat Cell Biol 2006;8:1448-1454. [PubMed: 17115026]

27. Zhu H, Geiman TM, Xi S, Jiang Q, Schmidtmann A, Chen T, Li E, Muegge K. Lsh is involved in de novo methylation of DNA. Embo J 2006;25:335-345. [PubMed: 16395332]

28. Myant K, Stancheva I. LSH cooperates with DNA methyltransferases to repress transcription. Mol Cell Biol 2008;28:215-226. [PubMed: 17967891]

29. Xi S, Zhu H, Xu H, Schmidtmann A, Geiman TM, Muegge K. Lsh controls Hox gene silencing during development. Proc Natl Acad Sci U S A 2007;104:14366-14371. [PubMed: 17726103]

30. Wilson AS, Power BE, Molloy PL. DNA hypomethylation and human diseases. Biochim Biophys Acta 2007;1775:138-162. [PubMed: 17045745]

31. Okano M, Bell DW, Haber DA, Li E. DNA methyltransferases Dnmt3a and Dnmt3b are essential for de novo methylation and mammalian development. Cell 1999;99:247-257. [PubMed: 10555141]

32. Yamada Y, Jackson-Grusby L, Linhart H, Meissner A, Eden A, Lin H, Jaenisch R. Opposing effects of DNA hypomethylation on intestinal and liver carcinogenesis. Proc Natl Acad Sci U S A 2005;102:13580-13585. [PubMed: 16174748]

33. Gaudet F, Hodgson JG, Eden A, Jackson-Grusby L, Dausman J, Gray JW, Leonhardt H, Jaenisch R. Induction of tumors in mice by genomic hypomethylation. Science 2003;300:489-492. [PubMed: 12702876]

34. Eden A, Gaudet F, Waghmare A, Jaenisch R. Chromosomal instability and tumors promoted by DNA hypomethylation. Science 2003;300:455. [PubMed: 12702868]

35. Lin H, Yamada Y, Nguyen S, Linhart H, Jackson-Grusby L, Meissner A, Meletis K, Lo G, Jaenisch R. Suppression of intestinal neoplasia by deletion of Dnmt3b. Mol Cell Biol 2006;26:2976-2983. [PubMed: 16581773]

36. Gupta A, Godwin AK, Vanderveer L, Lu A, Liu J. Hypomethylation of the synuclein gamma gene $\mathrm{CpG}$ island promotes its aberrant expression in breast carcinoma and ovarian carcinoma. Cancer Res 2003;63:664-673. [PubMed: 12566312]

37. Jia T, Liu YE, Liu J, Shi YE. Stimulation of breast cancer invasion and metastasis by synuclein gamma. Cancer Res 1999;59:742-747. [PubMed: 9973226]

38. Woloszynska-Read A, James SR, Link PA, Yu J, Odunsi K, Karpf AR. DNA methylation-dependent regulation of BORIS/CTCFL expression in ovarian cancer. Cancer Immun 2007;7:21. [PubMed: 18095639]

39. Cui H, Onyango P, Brandenburg S, Wu Y, Hsieh CL, Feinberg AP. Loss of imprinting in colorectal cancer linked to hypomethylation of H19 and IGF2. Cancer Res 2002;62:6442-6446. [PubMed: 12438232]

40. Walsh CP, Chaillet JR, Bestor TH. Transcription of IAP endogenous retroviruses is constrained by cytosine methylation. Nat Genet 1998;20:116-117. [PubMed: 9771701]

41. Miki Y, Nishisho I, Horii A, Miyoshi Y, Utsunomiya J, Kinzler KW, Vogelstein B, Nakamura Yz. Disruption of the APC gene by a retrotransposal insertion of L1 sequence in a colon cancer. Cancer Res 1992;52:643-645. [PubMed: 1310068]

42. Howard G, Eiges R, Gaudet F, Jaenisch R, Eden A. Activation and transposition of endogenous retroviral elements in hypomethylation induced tumors in mice. Oncogene 2008;27:404-408. [PubMed: 17621273]

43. Arai E, Kanai Y, Ushijima S, Fujimoto H, Mukai K, Hirohashi S. Regional DNA hypermethylation and DNA methyltransferase (DNMT) 1 protein overexpression in both renal tumors and corresponding nontumorous renal tissues. Int J Cancer 2006;119:288-296. [PubMed: 16453286]

44. Peng DF, Kanai Y, Sawada M, Ushijima S, Hiraoka N, Kitazawa S, Hirohashi S. DNA methylation of multiple tumor-related genes in association with overexpression of DNA methyltransferase 1 (DNMT1) during multistage carcinogenesis of the pancreas. Carcinogenesis 2006;27:1160-1168. [PubMed: 16537562]

45. Rhee I, Bachman KE, Park BH, Jair KW, Yen RW, Schuebel KE, Cui H, Feinberg AP, Lengauer C, Kinzler KW, Baylin SB, Vogelstein B. DNMT1 and DNMT3b cooperate to silence genes in human cancer cells. Nature 2002;416:552-556. [PubMed: 11932749] 
46. Rhee I, Jair KW, Yen RW, Lengauer C, Herman JG, Kinzler KW, Vogelstein B, Baylin SB, Schuebel KE. CpG methylation is maintained in human cancer cells lacking DNMT1. Nature 2000;404:10031007. [PubMed: 10801130]

47. Chen T, Hevi S, Gay F, Tsujimoto N, He T, Zhang B, Ueda Y, Li E. Complete inactivation of DNMT1 leads to mitotic catastrophe in human cancer cells. Nat Genet 2007;39:391-396. [PubMed: 17322882]

48. Jackson-Grusby L, Beard C, Possemato R, Tudor M, Fambrough D, Csankovszki G, Dausman J, Lee $\mathrm{P}$, Wilson C, Lander E, Jaenisch R. Loss of genomic methylation causes p53-dependent apoptosis and epigenetic deregulation. Nat Genet 2001;27:31-39. [PubMed: 11137995]

49. Egger G, Jeong S, Escobar SG, Cortez CC, Li TW, Saito Y, Yoo CB, Jones PA, Liang G. Identification of DNMT1 (DNA methyltransferase 1) hypomorphs in somatic knockouts suggests an essential role for DNMT1 in cell survival. Proc Natl Acad Sci U S A 2006;103:14080-14085. [PubMed: 16963560]

50. Brown KD, Robertson KD. DNMT1 knockout delivers a strong blow to genome stability and cell viability. Nat Genet 2007;39:289-290. [PubMed: 17325677]

51. Beaulieu N, Morin S, Chute IC, Robert MF, Nguyen H, MacLeod AR. An essential role for DNA methyltransferase DNMT3B in cancer cell survival. J Biol Chem 2002;277:28176-28181. [PubMed: 12015329]

52. Linhart HG, Lin H, Yamada Y, Moran E, Steine EJ, Gokhale S, Lo G, Cantu E, Ehrich M, He T, Meissner A, Jaenisch R. Dnmt3b promotes tumorigenesis in vivo by gene-specific de novo methylation and transcriptional silencing. Genes Dev 2007;21:3110-3122. [PubMed: 18056424]

53. Biniszkiewicz D, Gribnau J, Ramsahoye B, Gaudet F, Eggan K, Humpherys D, Mastrangelo MA, Jun Z, Walter J, Jaenisch R. Dnmt1 overexpression causes genomic hypermethylation, loss of imprinting, and embryonic lethality. Mol Cell Biol 2002;22:2124-2135. [PubMed: 11884600]

54. Hernandez-Munoz I, Taghavi P, Kuijl C, Neefjes J, van Lohuizen M. Association of BMI1 with polycomb bodies is dynamic and requires PRC2/EZH2 and the maintenance DNA methyltransferase DNMT1. Mol Cell Biol 2005;25:11047-11058. [PubMed: 16314526]

55. Li B, Zhou J, Liu P, Hu H, Jin H, Shimono Y, Takahashi M, Xu G. Polycomb protein Cbx4 promotes SUMO modification of de novo DNA methyltransferase Dnmt3a. Biochem J 2007;405:369-378. [PubMed: 17439403]

56. Taghavi P, van Lohuizen M. Developmental biology: two paths to silence merge. Nature 2006;439:794-795. [PubMed: 16482140]

57. McGarvey KM, Greene E, Fahrner JA, Jenuwein T, Baylin SB. DNA methylation and complete transcriptional silencing of cancer genes persist after depletion of EZH2. Cancer Res 2007;67:50975102. [PubMed: 17545586]

58. Rajasekhar VK, Begemann M. Concise review: roles of polycomb group proteins in development and disease: a stem cell perspective. Stem Cells 2007;25:2498-2510. [PubMed: 17600113]

59. Negishi M, Saraya A, Miyagi S, Nagao K, Inagaki Y, Nishikawa M, Tajima S, Koseki H, Tsuda H, Takasaki Y, Nakauchi H, Iwama A. Bmil cooperates with Dnmt1-associated protein 1 in gene silencing. Biochem Biophys Res Commun 2007;353:992-998. [PubMed: 17214966]

60. Kim SH, Park J, Choi MC, Park JH, Kim HP, Lee JH, Oh DY, Im SA, Bang YJ, Kim TY. DNA methyltransferase $3 \mathrm{~B}$ acts as a co-repressor of the human polycomb protein $\mathrm{hPc} 2$ to repress fibroblast growth factor receptor 3 transcription. Int J Biochem Cell Biol. 2008

61. Dunican DS, Ruzov A, Hackett JA, Meehan RR. xDnmt1 regulates transcriptional silencing in preMBT Xenopus embryos independently of its catalytic function. Development 2008;135:1295-1302. [PubMed: 18305009]

62. Bernstein E, Duncan EM, Masui O, Gil J, Heard E, Allis CD. Mouse polycomb proteins bind differentially to methylated histone $\mathrm{H} 3$ and RNA and are enriched in facultative heterochromatin. Mol Cell Biol 2006;26:2560-2569. [PubMed: 16537902]

63. Lyst MJ, Stancheva I. A role for SUMO modification in transcriptional repression and activation. Biochem Soc Trans 2007;35:1389-1392. [PubMed: 18031228]

64. Ohm JE, Baylin SB. Stem cell chromatin patterns: an instructive mechanism for DNA hypermethylation? Cell Cycle 2007;6:1040-1043. [PubMed: 17457052] 
65. Fouse SD, Shen Y, Pellegrini M, Cole S, Meissner A, Van Neste L, Jaenisch R, Fan G. Promoter $\mathrm{CpG}$ methylation contributes to ES cell gene regulation in parallel with Oct4/Nanog, PcG complex, and histone H3 K4/K27 trimethylation. Cell Stem Cell 2008;2:160-169. [PubMed: 18371437]

66. Ohm JE, McGarvey KM, Yu X, Cheng L, Schuebel KE, Cope L, Mohammad HP, Chen W, Daniel VC, Yu W, Berman DM, Jenuwein T, Pruitt K, Sharkis SJ, Watkins DN, Herman JG, Baylin SB. A stem cell-like chromatin pattern may predispose tumor suppressor genes to DNA hypermethylation and heritable silencing. Nat Genet 2007;39:237-242. [PubMed: 17211412]

67. Ehrich M, Turner J, Gibbs P, Lipton L, Giovanneti M, Cantor C, van den Boom D. Cytosine methylation profiling of cancer cell lines. Proc Natl Acad Sci U S A 2008;105:4844-4849. [PubMed: 18353987]

68. Ehrlich M, Jackson K, Weemaes C. Immunodeficiency, centromeric region instability, facial anomalies syndrome (ICF). Orphanet J Rare Dis 2006;1:2. [PubMed: 16722602]

69. Hansen RS, Stoger R, Wijmenga C, Stanek AM, Canfield TK, Luo P, Matarazzo MR, D'Esposito M, Feil R, Gimelli G, Weemaes CM, Laird CD, Gartler SM. Escape from gene silencing in ICF syndrome: evidence for advanced replication time as a major determinant. Hum Mol Genet 2000;9:2575-2587. [PubMed: 11063717]

70. Kondo T, Bobek MP, Kuick R, Lamb B, Zhu X, Narayan A, Bourc'his D, Viegas-Pequignot E, Ehrlich M, Hanash SM. Whole-genome methylation scan in ICF syndrome: hypomethylation of non-satellite DNA repeats D4Z4 and NBL2. Hum Mol Genet 2000;9:597-604. [PubMed: 10699183]

71. Tao Q, Huang H, Geiman TM, Lim CY, Fu L, Qiu GH, Robertson KD. Defective de novo methylation of viral and cellular DNA sequences in ICF syndrome cells. Hum Mol Genet 2002;11:2091-2102. [PubMed: 12189161]

72. Ueda Y, Okano M, Williams C, Chen T, Georgopoulos K, Li E. Roles for Dnmt3b in mammalian development: a mouse model for the ICF syndrome. Development 2006;133:1183-1192. [PubMed: 16501171]

73. Gowher H, Jeltsch A. Molecular enzymology of the catalytic domains of the Dnmt3a and Dnmt3b DNA methyltransferases. J Biol Chem 2002;277:20409-20414. [PubMed: 11919202]

74. Xie ZH, Huang YN, Chen ZX, Riggs AD, Ding JP, Gowher H, Jeltsch A, Sasaki H, Hata K, Xu GL. Mutations in DNA methyltransferase DNMT3B in ICF syndrome affect its regulation by DNMT3L. Hum Mol Genet 2006;15:1375-1385. [PubMed: 16543361]

75. Jin B, Tao Q, Peng J, Soo HM, Wu W, Ying J, Fields CR, Delmas AL, Liu X, Qiu J, Robertson KD. DNA methyltransferase 3B (DNMT3B) mutations in ICF syndrome lead to altered epigenetic modifications and aberrant expression of genes regulating development, neurogenesis and immune function. Hum Mol Genet 2008;17:690-709. [PubMed: 18029387]

76. Lee TI, Jenner RG, Boyer LA, Guenther MG, Levine SS, Kumar RM, Chevalier B, Johnstone SE, Cole MF, Isono K, Koseki H, Fuchikami T, Abe K, Murray HL, Zucker JP, Yuan B, Bell GW, Herbolsheimer E, Hannett NM, Sun K, Odom DT, Otte AP, Volkert TL, Bartel DP, Melton DA, Gifford DK, Jaenisch R, Young RA. Control of developmental regulators by Polycomb in human embryonic stem cells. Cell 2006;125:301-313. [PubMed: 16630818]

77. Matarazzo MR, Boyle S, D'Esposito M, Bickmore WA. Chromosome territory reorganization in a human disease with altered DNA methylation. Proc Natl Acad Sci U S A 2007;104:16546-16551. [PubMed: 17923676] 


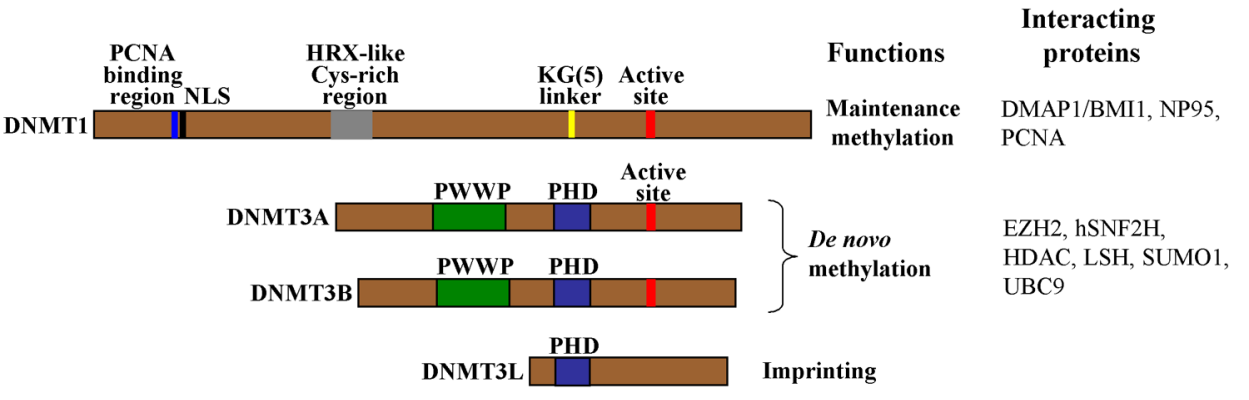

Fig. 1.

The DNA methylation machinery. The mammalian DNA methyltransferase family consists of DNMT1, DNMT3A, DNMT3B, and DNMT3L. DNMT1 is considered the maintenance methyltransferase due to its high activity and preference for hemimethylated DNA during DNA replication. DNMT3A and DNMT3B are de novo methyltransferases. Shown in this figure is a schematic of the DNA methyltransferases with their key functional domains and proteinprotein interaction domains indicated. All of the active DNA methyltransferases contain the active site motif IV in the C-terminal region (red box). DNMT1 contains a region required for its interaction with PCNA, which is adjacent to the nuclear localization signal (NLS). The Nterminal region of DNMT1 also contains a cysteine -rich HRX-like region and a lysine-glycine repeat $(\mathrm{KG}(5))$ region. DNMT3A and DNMT3B contain plant homeodomain (PHD) and PWWP domains. These two domains are required for targeting DNMT3A and DNMT3B to pericentromeric heterochromatin and contribute to protein-protein interactions by recognition of histone modifications. Interacting proteins relevant to this review are also listed. 
A)
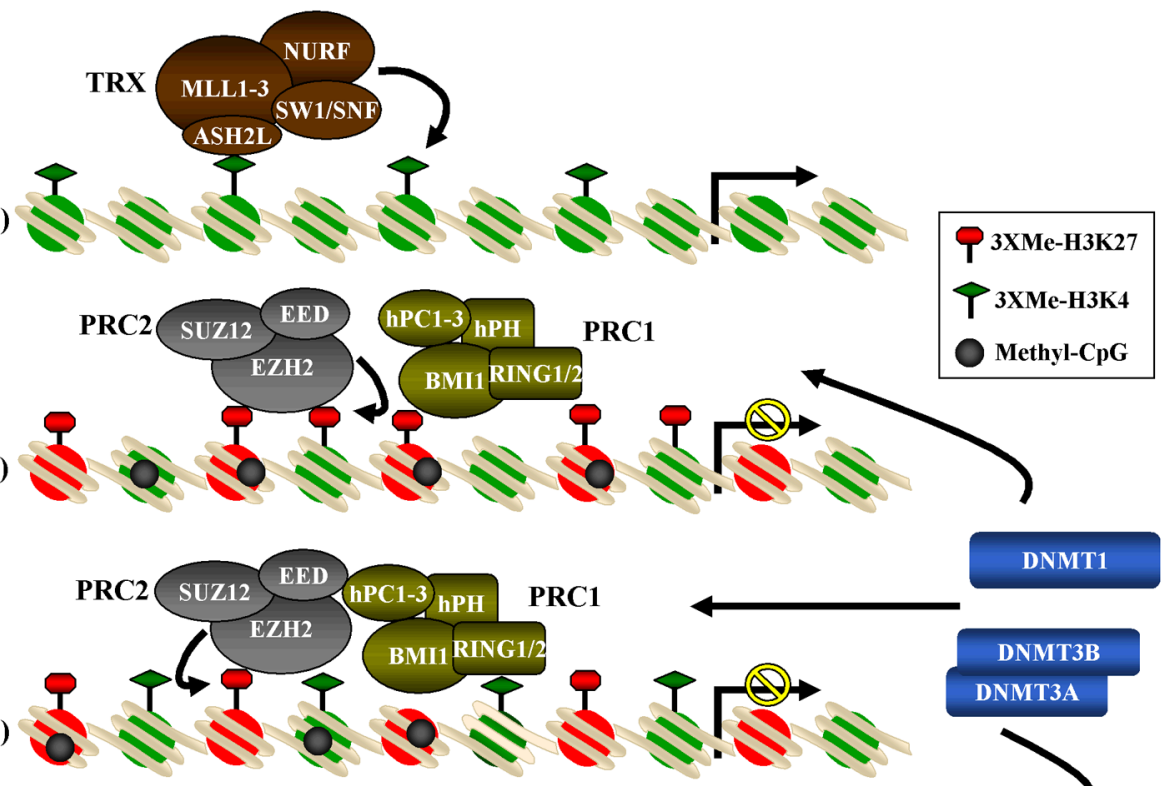

DNMT1

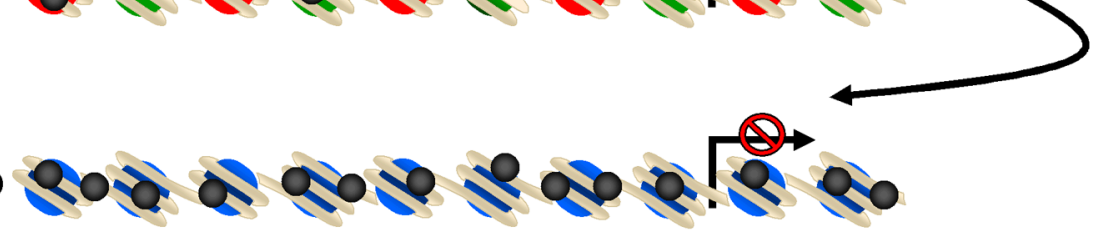

Fig. 2.

Transcriptional states during differentiation and their associated chromatin modifications. (A) The mammalian trithorax complex (TRX), consisting of the homologs of yeast and Drosophila SET domain containing histone H3K4 methyltransferases MLL1-3 and ASH2L, are responsible for establishing $\mathrm{H} 3 \mathrm{~K} 4$ trimethylation. $\mathrm{H} 3 \mathrm{~K} 4$ trimethylation is associated with active transcription represented by the green nucleosomes. (B-C) The polycomb protein complexes PRC1 and PRC2 mediate gene silencing. EZH2 in PRC2 mediates H3K27 trimethylation and also interacts with DNMTs. RING1/2 in the PRC1 complex mediates H2AK119 monoubiquitination. Both H3K27 trimethylation and H2AK119 monoubiquitination are histone marks associated with transcriptional repression (represented by red nucleosomes). Most pluripotency and self-renewal associated genes are marked with H3K4 trimethylation while some differentiation-associated genes are marked bivalently with H3K27 and H3K4 trimethylation. (D) Late differentiation-associated genes are marked by DNA methylation and do not generally contain H3K4 and H3K27 methylation marks (represented by blue nucleosomes). DNA methylation may also play a role in the chromatin states shown in B and $\mathrm{C}$. 


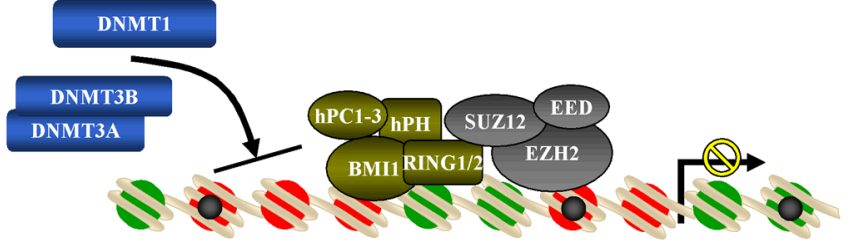

A)

OR

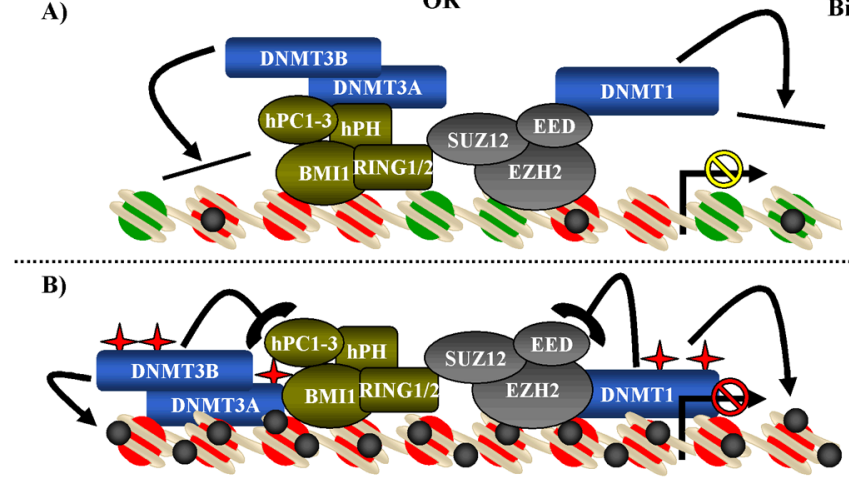

ES cells

Bivalent: H3K4, H3K27 methylation Low/absent DNA methylation

Fig. 3.

DNA methyltransferase-polycomb complex interactions in development and cancer. (A) In normal pluripotent cells (ES cells in this case, although tissue-specific stem cells may be similar), genes involved in differentiation are expressed at low levels or are repressed. These genes tend to be marked by both activating (trimethylated $\mathrm{H} 3 \mathrm{~K} 4,3 \mathrm{XMe}-\mathrm{H} 3 \mathrm{~K} 4$ ) and repressive (trimethylated H3K27, 3XMe-H3K27) marks. A subset of these genes may also be marked by DNA methylation. The regulation of the DNMTs in this state remains unknown. The DNMTs may constitutively associate with polycomb complexes but be rendered inactive or in a low activity state (bottom panel). Alternatively, other chromatin marks or differences in the activity/ composition of polycomb complexes prevent DNMT recruitment (top panel). For example, the 3XMe-H3K4 may inhibit DNMT3L-mediated recruitment of de novo DNA

methyltransferases. In this bivalent state, genes are able to respond to external developmental cues. (B) In tumor cells or tumor initiating cells (TIC), we propose that normal regulation of the DNMTs is disrupted. This may be due to aberrant recruitment of DNMTs to genes normally repressed by polycomb complexes and/or a change in the activity of bound DNMTs, possibly by post-translational modifications like sumoylation (indicated by the red stars) or a change in the chromatin environment such as acquisition of other repressive histone marks (e.g. trimethylated H3K9). Pro-differentiation genes are then locked in an 'off' state due to dense DNA methylation and cells no longer properly respond to differentiation cues and/or they acquire enhanced self-renewal capacity. Once dense DNA methylation is present, the DNMTs may have a role in maintaining PRC1/PRC2 binding. 

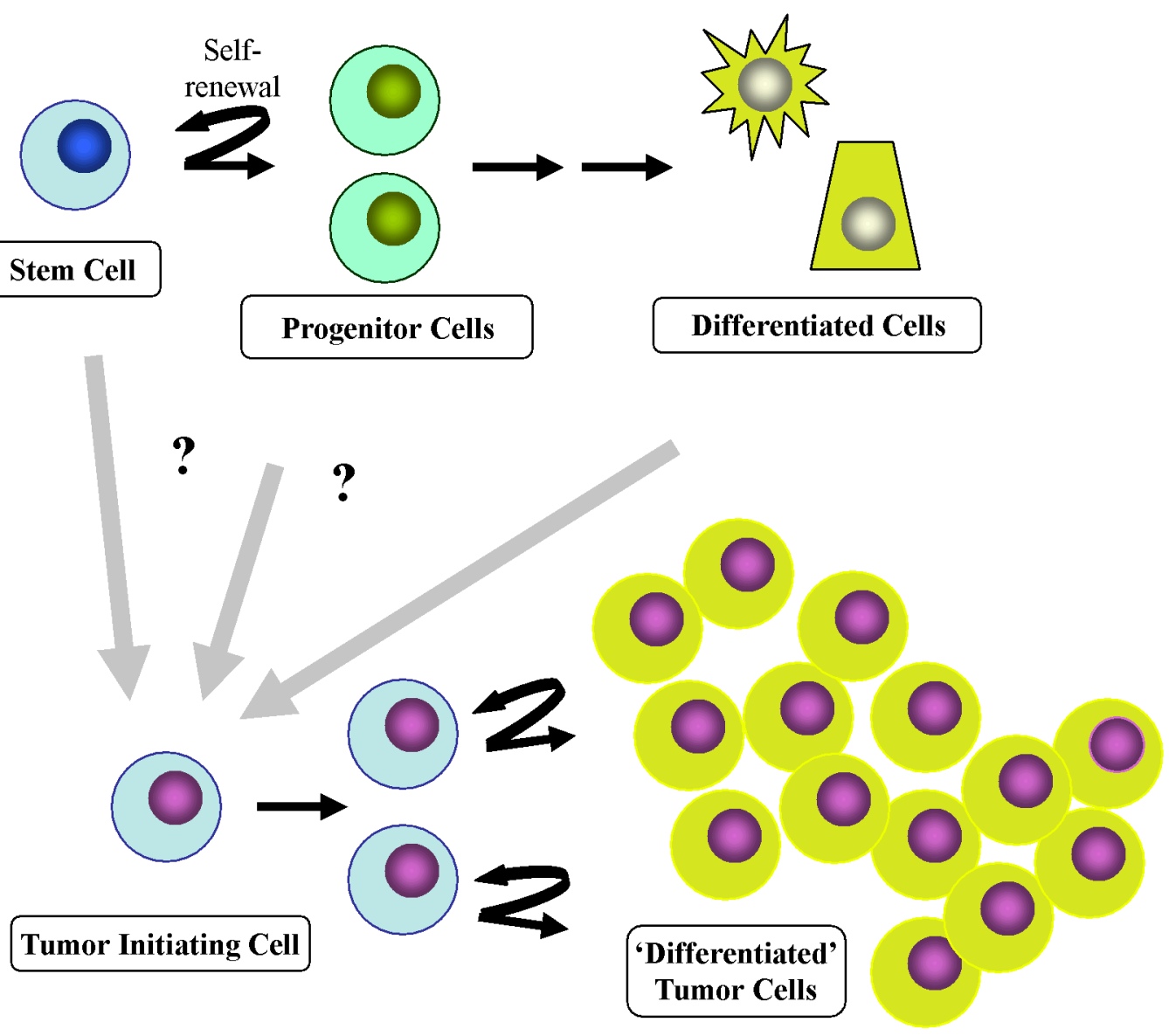

Fig. 4.

The cancer stem cell theory. Normal stem cell self-renewal is a tightly regulated process. The resulting progenitor cells are unable to self-renew but can undergo a finite number of divisions and are capable of differentiation. Transformation of a normal stem cell or a dedifferentiated somatic cell by genetic or epigenetic inactivation of tumor suppressor genes or activation of oncogenes can lead to a loss of regulated self-renewal resulting in a cancer stem cell (or tumor initiating cell, TIC), unregulated expansion of the TICs, and aberrant differentiation. It is unknown whether TICs arise from normal stem cells, transiently amplifying progenitors that have gained self-renewal capability, or dedifferentiated somatic cells. 